\title{
ENTREVISTA REALIZADO COM O PROFESSOR DR. PAULO ROBERTO OLIVEIRA, DOCENTE DA FACULDADE DE EDUCAÇÃO FÍSICA DA UNICAMP.
}

Gustavo Luis Gutierrez

Faculdade de Educação Física

UNICAMP

Paulo Roberto

1.- Fale um pouco de você, sua carreira e seu vínculo com a educação física.

A minha escolha pela profissão de professor de Educação Física tem relação com vários fatos que somados motivaram meu envolvimento com a área; desde a adolescência, atraído pelo excelente programa da disciplina Educação Física Escolar, ministrada por um grande educador, fui gradativamente percebendo o desporto como um fenômeno social multifacetado, e reconhecendo a importância de uma ação competente e comprometida com o desenvolvimento educacional de uma comunidade (pequena comunidade).

Orientado pelos princípios de co-gestão, co-participação e co-responsabilidade, o seu Zé (como o chamávamos respeitosamente) propiciou à minha geração vivências motoras diversificadas durante as aulas de educação física usando atividades prazerosas como caminhadas, passeios campestres, acampamentos, acantonamentos, travessias de lagos, passeio nas fazendas, competições escolares em diferentes desportos, sem jamais se esquecer das bases humanitárias gerais do movimento desportivo, orientando a prática para o desenvolvimento da consciência e do sentimento, colaboração, amizade e solidariedade entre pessoas; a Educação Física de minha adolescência conseguiu despertar não apenas a mim mas toda minha geração para uma vida ativa fisicamente, assim como sensibilizou a comunidade de Itapira para as potencialidades educacionais de uma disciplina escolar bem conduzida.

Também considero que as minhas vivências desportivas competitivas como atleta do Esporte Clube Pinheiros e da seleção brasileira de atletismo também contribuíram para minha formação como desportista e cidadão. Participei de eventos competitivos dentro e fora do Brasil; embora a auto superação e a obtenção de bons resultados desportivos tenham orientado minha prática, tive oportunidade de conhecer pessoas, países, culturas e valores que influenciaram positivamente no meu conhecimento e comportamento durante minha trajetória de vida. 
Cursei a Escola de Educação Física entre 1968-1970; no ano seguinte (1971) fui aprovado no curso de técnico desportivo em atletismo quando fui convidado para atuar como instrutor voluntário naquela escola no ano de 1972; como docente, ministrei aulas de treinamento desportivo e atletismo na FEFISA (Faculdade de Educação Física de Santo André) e Faculdade de Educação Física de Guarulhos; ministrei aulas de Educação Física no Colégio Estadual de Itapevi e Colégio Municipal Alcina Dantas Feijão (São Caetano do Sul), respectivamente em 1971 e 1972; participei do grupo de técnicos esportivos que implantou a prática da Educação Física na USP (CEPEUSP), sob o comando do inesquecível Professor Antonio Boaventura da Silva (1972); em 1973 fui aprovado em concurso público na Universidade Estadual de Londrina onde fui docente por 20 anos; ainda no Estado do Paraná, atuei como professor em colégios públicos, universidade privada e, como preparador físico e técnico de futebol na equipe do Londrina Esporte Clube (1983-1986).

Entre 1987 e 1991, fui diretor técnico da Fundação de Esportes do Paraná quando coordenei a implantação e implementação da Política de Esportes, uma verdadeira revolução organizacional naquele Estado.

A partir de 1993, iniciei minhas atividades acadêmicas no Departamento de Ciências do Esporte da Faculdade de Educação Física da UNICAMP, onde estou há 15 anos com aposentadoria prevista para o próximo ano; o mestrado em Educação Física foi desenvolvido junto a Faculdade de Educação Física de USP (1977-1982) e o doutorado na Faculdade de Educação Física da UNICAMP (1993-1998)

\section{2.- Como você enxerga a evolução do campo do treinamento esportivo e a incorporação de novos métodos no treinamento de alto rendimento?}

O conceito das ações do treinamento surgiu baseado unicamente em experiências práticas ou deduções análogas, quase sempre sem comprovação específica ou sustentação científica.

Evidentemente que para a teoria do treinador, as experiências resumidas e sistematizadas de muitos especialistas em treinamento desportivo e a experiência própria subjetiva e refletida representam quase sempre as precondições para ações não substituíveis por nenhum conhecimento científico. 
No entanto, ainda que considerado de fundamental importância a experiência prática dos treinadores, no presente momento, parece pouco provável que apenas a intuição destes dedicados profissionais dê conta de resolver os complexos e multivariados problemas do desporto de competição.

É inegável que o conceito de treinamento desportivo sofreu modificações sustentadas por novos conhecimentos de áreas afins, com reflexo direto sobre os desempenhos competitivos bastando que se observe a evolução dos recordes mundiais e olímpicos, o nível da condição atlética dos desportistas mais destacados da atualidade, além do crescente número de desportistas que obtêm resultados expressivos, só obtidos por poucos atletas há poucos anos atrás.

O treinamento desportivo pode ser considerado como a forma fundamental de preparação do desportista, baseado em exercícios sistemáticos representando em sua essência, um processo organizado pedagogicamente com o objetivo de dirigir a evolução do desportista (seu aperfeiçoamento desportivo). Também pode ser entendido como o exercício funcional planejado na área corporal ou mental, com o objetivo de desempenho individual máximo, principalmente no desporto de competição.

Um dos grandes avanços na área do treinamento desportivo foi a sua ampliação conceitual uma vez que tanto do ponto de vista pedagógico como metodológico, devem ser objetivados efeitos positivos de treinamento tanto nas características comportamentais motoras, como nas emocionais e intelectuais, ou seja, um entendimento atual de que desempenho no desporto é uma questão complexa e multivariada.

Infelizmente, em nosso país, apesar dos trinta e um anos de pós- graduação, pesquisas e publicações oriundas do desporto, a aproximação entre universidades e federações de confederações, pesquisadortreinador ainda não se concretizou, ou ainda, está restrita a isoladas iniciativas.

A ampliação das possibilidades de aplicação dos modernos meios e métodos testados e comprovados tem sido um desafio para aqueles que tentam administrar a aproximação teoria e prática e vice versa, que, seja por prepotência ou insegurança, pouco evoluiu. Por outro lado, recentemente, alguns clubes brasileiros vêm dando um exemplo positivo, tomando a iniciativa de incluir em seus organogramas a figura do assessor científico permitindo a interação entre treinador/assessor objetivando desenvolver o processo de preparação do desportista do clube com maior probabilidade de acerto; é obvio que tal procedimento tem refletido no desempenho internacional dos atletas brasileiros quando a serviço da confederação. A natação, futebol e o voleibol podem ser tomados como bons exemplos de interação teoria e prática. 
Portanto, a teoria do treinamento desportivo tem evoluído à medida que os conhecimentos científicos se acumulam e se disponibilizam na esfera geral do desporto, no entanto, administrativamente continuamos carentes de recursos humanos oriundos da área, com formação especializada em nível de pós-graduação, além de continuarmos reféns de políticas partidárias, lobbies de confederações que administram estruturas ainda organizadas autocraticamente ou, subjugados aos interesses dos empresários do desporto que só se orientam pelos princípios da lucratividade.

\section{3- Há uma reclamação, mais ou menos geral e permanente, sobre as políticas públicas no esporte. Qual a sua opinião?}

Realmente, nosso país não tem o hábito de discutir políticas antes do início de governos seja no município, estado ou no país. Não se vota em políticas, mas, em pessoas; portanto, a maior parte dos dirigentes desportivos raramente é oriunda do desporto, ou ainda têm o desporto como essência de sua formação profissional. Assim, muitos pára-quedistas são colocados em funções administrativas sem a devida preparação. Como é que tais pessoas vão poder organizar uma discussão sobre políticas públicas?

Por outro lado, temos como tradição a ruptura com idéias que estão dando bons resultados ainda que em governos de mesmo partido que se sucedem.

A ausência de políticas bem definidas e de longo prazo no país faz com que os recursos sejam prioritariamente gastos com o desporto de rendimento por conta da presença oportunista de instituições organizadas (clubes, federações, confederações), ao invés de se dirigir para o desporto educacional e de participação; assim, vamos tapando o sol com a peneira deixando de focar a questão principal que é a democratização do desporto, o desporto acessível a todos, etc. O artigo 217 da constituição brasileira que parecia ser uma grande conquista, "é dever do Estado fomentar práticas formais e não formais, como direito de cada um..." está muito distante da realidade; assim, alguns estudiosos da legislação desportiva destacam-se que "ao salientar o dever do Estado, o faz com o sentido de obrigação jurídica, sem contudo esclarecer, dentre os órgãos estatais, quem seria obrigado a fomentar as práticas desportivas, comprometendo, nessa ótica, a eficácia e, a dimensão aplicativa dos ideais desportivos"; 
4.- Como você percebe a apropriação de práticas originais do alto rendimento fora de seu contexto original (escolas, academias, espaços de lazer, etc.)?

As características peculiares de cada uma das manifestações desportivas (rendimento, educacional, participação) estão muito bem definidas no meio acadêmico e, em decorrência, no meio profissional; portanto, os profissionais de educação física devem conhecer de forma muito clara que os princípios específicos do sistema de preparação do desportista de alto rendimento (manipulação dos componentes da carga, conhecimento dos diferentes modelos de estruturação do treinamento, sistema de controle, etc.), só devem ser aplicados neste peculiar ambiente do desporto; por outro lado, devem estar cientes que certas práticas bem sucedidas no desporto de alto rendimento (a sofisticação do processo de gestão, as peculiaridades das parcerias com a iniciativa privada, a necessidade de estabelecimento de metas objetivas, a adoção de sofisticados sistemas de controle da eficiência da relação custo benefício, etc.) precisam ser incorporadas pelas outras manifestações do desporto, como estratégia determinante para a consolidação do desporto educacional e participação.

\section{5.- O que você nos pode dizer sobre essa relação, tão vinculada pela mídia, entre esporte e saúde?}

As diferentes formas de exercitação historicamente conhecidas, anteriores ao desporto de competição e praticadas nos diferentes contextos, foram instrumentalizadas para cumprir finalidades no âmbito do corpo e da saúde. Portanto, o desporto está inquestionavelmente associado ao corpo e à saúde. Pela prática do exercício físico, pode-se intervir no corpo e na saúde. As diferentes manifestações do desporto podem ter um papel importante no sentido da preservação da saúde da sociedade, embora a mídia muitas vezes desconheça os conceitos relativos à aptidão física. Já foi bem tratada e delimitada, no meio acadêmico, o conceito de aptidão relacionado à saúde do cidadão e o conceito de aptidão física relacionado ao rendimento desportivo, ou seja, aquele relacionado às habilidades desportivas, em especial dos desportistas de competição.

Evidente, embora as ciências humanas relacionem várias doenças da civilização contemporânea à diminuição da prática de atividade física e, tal evidência, nem sempre pode ser confirmada em sua totalidade, enquanto não surgir outro mito ou verdade, os professores de Educação Física devem ter o compromisso de defender a idéia do desporto como uma fonte inesgotável de saúde, principalmente 
quando sua prática respeita os limites do homem, sua individualidade biológica, suas experiências desportivas anteriores e seus interesses.

A mídia deveria entender que o desporto de rendimento utiliza o treinamento desportivo como uma forma especializada de preparação, com base em exercícios sistematizados, com o objetivo de dirigir a evolução do desportista para seu aperfeiçoamento máximo, capacitando-o a propiciar espetáculo. Transferir tais concepções para outras manifestações desportivas, outros níveis de possibilidades humanas é um grande equívoco.

A Educação Física tem um papel relevante na reflexão sobre o fenômeno do desporto na sociedade.

\section{6.- E sobre dopping, ética e a hipercompetitividade no esporte de alto rendimento? E, só para provocar, é possível ser campeão olímpico sem dopping?}

Aí está uma questão bastante complexa, pois o aumento significativo do número de atletas suspensos pela utilização de drogas proibidas tem relação direta com as atitudes das autoridades desportivas em detectar as drogas e afastar definitivamente tais práticas da arena desportiva.

Se um dos princípios fundamentais do desporto de competição é que o mesmo respeite a igualdade entre desportista e equipes e, se a droga, pela sua ação estimulante, anabolizante, etc. torna um desportista mais competitivo do que outro, deve-se eliminar tal possibilidade, nos limites da capacidade dos laboratórios em detectar. É muito provável que o elenco das drogas não detectáveis seja muito maior do que as detectáveis.

$\mathrm{Na}$ história do desporto de competição podemos distinguir momentos peculiares com seus diferentes paradigmas: o desporto enquanto manifestação cultural, o desporto como veículo de propaganda política, o desporto como negócio e como tal deve ser altamente rentável; muitas vezes tais enfoques mascararam os objetivos fundamentais da educação física; assim a busca das vantagens e das vitórias a qualquer custo, sempre foi uma preocupação de alguns.

Por outro lado, os atletas da Etiópia, Quênia, nas provas de fundo e, mais recentemente, os velocistas jamaicanos do atletismo tem dado demonstração que descobertas as potencialidades genéticas e 
desenvolvidos os meios e métodos de preparação desportiva os talentos podem aflorar e ocupar lugar de destaque no desporto mundial e olímpico, sem que se precise lançar mão da utilização de drogas proibidas; afinal, supor que tais desportistas fazem uso de drogas sem ter a certeza, seria o mesmo que duvidar dos eméritos cientistas de diferentes países, membros participantes dos laboratórios conveniados com os órgãos internacionais que regulam o desporto, que se dedicam às análises visando coibir a utilização das drogas; ou ainda, seria o mesmo que questionar a IAAF e o COI, instituições que cuidam com rigor a questão do exame antidoping.

7.- Permanece na educação física uma separação, ou especialização, entre licenciatura e bacharelado. Qual seu ponto de vista com relação às vantagens e desvantagens do modelo?

A Educação Física enquanto disciplina do currículo escolar precisa desenvolver suas próprias premissas tendo presente sua relação com disciplinas biológicas, exatas e humanas. No entanto, nada mais claro que o caminho a trilhar pela licenciatura deve ter uma estrutura curricular própria, com o predomínio de especialistas formados em educação física com aprofundamento nas áreas das ciências humanas.

Embora consideremos que o estudo da ação motora reflita no estudo do homem que executa essa ação, na licenciatura deve-se transferir a essência da prática desportiva para o praticante, não se focando apenas na execução. O desporto deve ser percebido enquanto prática humana. Aqui, vejo o desporto como meio de desenvolvimento, educação e preparação multifacetada para a vida.

O bacharelado deve ser dirigido a uma ação essencialmente profissionalizante e, aqui, sem perder jamais o enfoque educacional deve-se pensar nos especialistas das diferentes áreas de estudos como fisiologia, bioquímica, biomecânica, psicologia, treinamento desportivo, medidas e avaliação, etc. com enfoque dirigido a segmentos específicos da sociedade.

$\mathrm{Na}$ minha concepção o novo profissional do desporto deve em primeiro lugar estar ciente das possibilidades de atuação na área; a seguir, em função da aptidão, deverá buscar estrutura de curso que mais se identifica com a sua área de interesse. Ainda vivemos o sonho de uma atuação abrangente em que supúnhamos ser capaz de dar conta do fenômeno desportivo em toda a sua abrangência; para a evolução da área deveremos buscar um modelo de formação mais especializada e delimitada. 


\section{Gustavo Luis Gutierrez}

Faculdade de Educação Física

UNICAMP 